\title{
COMPLEXIDADE DA ELABORAÇÃO DE UM PROTOCOLO PARA REUTILIZAÇÃO DE MATERIAIS DE USO ÚNICO
}

\author{
Rafael Queiroz de Souza* \\ Cristiane Schmitt** \\ Lilian Machado Torres*** \\ Kazuko Uchikawa Graziano**** \\ Rúbia Aparecida Lacerda***** \\ Ruth Natália Teresa Turrini ${ }^{\star \star \star \star \star \star *}$
}

\begin{abstract}
RESUMO
No Brasil, o reúso de materiais de uso único é uma realidade. A Resolução Específica 2.606/2006 da Agência Nacional de Vigilância Sanitária (ANVISA), que dispõe sobre as diretrizes para a elaboração, validação e implantação dos protocolos de reprocessamento de produtos médicos, enfatiza aspectos microbiológicos e recomenda a descrição detalhada das fases de limpeza, enxágue, secagem, desinfecção, empacotamento, esterilização, rotulagem e acondicionamento. Entende-se que, para elaborar um protocolo de reprocessamento, outros aspectos relacionados à segurança devem ser incluídos, como a avaliação da integridade e da funcionalidade dos materiais reusados, da presença de biofilmes, de endotoxinas, de resíduos de proteínas e de partículas priônicas e de outros resíduos tóxicos dos produtos utilizados na limpeza e esterilização. Diante destas fragilidades da legislação, o presente artigo de reflexão se propôs discorrer sobre os outros riscos inerentes ao reúso de materiais de uso único, além daqueles diretamente relacionados à infecção.
\end{abstract}

Palavras-chave: Controle de Risco. Segurança. Enfermagem.

\section{INTRODUÇÃO}

No Brasil, o reúso de materiais de uso único é uma realidade cujos riscos não foram suficientemente explorados. Esta prática quase sempre é justificada pelo alto custo dos materiais, muitas vezes, não adequadamente calculado. Um estudo realizado com indivíduos diabéticos encontrou $81 \%$ deles reutilizando agulhas e seringas para aplicação de insulina; tal achado evidencia claramente a relação entre o reúso e a tentativa de mitigação dos gastos ${ }^{(1)}$. Por outro lado, uma revisão sistemática que avaliou a segurança e a eficácia do reúso de cateteres de uso único para eletrofisiologia apontou que, sem justificativa convincente e arbitrariamente, alguns rótulos de materiais foram modificados para "de uso único", provavelmente visando interesse econômico por parte dos fabricantes ${ }^{(2)}$.
O consenso quanto ao reúso de materiais de uso único não é fácil, especialmente quando se trata de materiais complexos. Os materiais de uso único geralmente não são desmontáveis para a limpeza e, quando esta etapa não é garantida, a desinfecção ou a esterilização serão ineficazes.

No Brasil, a Resolução Específica 2.606/2006 da Agência Nacional de Vigilância Sanitária (ANVISA), que "dispõe sobre as diretrizes para elaboração, validação e implantação de protocolos de reprocessamento de produtos médicos e dá outras providências", define o reprocessamento de materiais como "processo de limpeza e desinfecção ou esterilização a ser aplicado a produtos médicos, de forma a garantir o desempenho e a segurança". Segundo o referido documento legal, a garantia do desempenho e da segurança do produto poderá ser obtida pela implantação e validação de protocolos de reprocessamento ${ }^{(3)}$, fica sob a

\footnotetext{
* Enfermeiro. Doutorando pelo Programa de Pós-Graduação em Enfermagem na Saúde do Adulto da Escola de Enfermagem da USP. E-mail: rafaelqsouza@hotmail.com

** Enfermeira. Doutoranda pelo Programa de Pós-Graduação em Enfermagem na Saúde do Adulto da Escola de Enfermagem da USP. E-mail: cristianeschmmitt@yahoo.com.br

*** Enfermeira. Mestranda pelo Programa de Pós-Graduação em Enfermagem na Saúde do Adulto da Escola de Enfermagem da USP. E-mail: lilian.torres@superig.com.br

**** Enfermeira. Professora Titular do Departamento de Enfermagem Médico-Cirúrgica da Escola de Enfermagem da USP. E-mail:kugrazia@usp.br

${ }^{\star * \star \star \star}$ Enfermeira. Professora Associada do Departamento de Enfermagem Médico-Cirúrgica da Escola de Enfermagem da USP. E-mail: rlacerda@usp.br

${ }_{\star \star \star \star \star \star \star}$ Enfermeira. Doutora. Professora do Departamento de Enfermagem Médico-Cirúrgica da Escola de Enfermagem da USP. E-mail: rturrini@usp.br
} 
responsabilidade do estabelecimento de assistência à saúde e deve contemplar testes de esterilidade, apirogenicidade, atoxicidade e integridade; porém a resolução não estabelece os métodos e parâmetros mínimos de segurança.

Numa análise mais profunda, percebe-se que a legislação entende que a segurança está atrelada prioritariamente a aspectos microbiológicos, pois enfatiza a necessidade de descrever detalhadamente as fases de limpeza, enxágue, secagem, desinfecção, empacotamento, esterilização, rotulagem e acondicionamento, sem contemplar os testes e métodos destinados aos outros aspectos relacionados à segurança.

Com base nessas fragilidades, identificou-se a necessidade de discorrer sobre os outros riscos inerentes ao reprocessamento de materiais de uso único, além daqueles diretamente relacionados à infecção, para que os mesmos sejam considerados na elaboração do protocolo para reúso desta categoria de materiais na assistência à saúde.

\section{MÉTODO}

Este estudo caracterizou-se como um artigo de reflexão tendo como marco teórico a legislação atual sobre práticas de processamento de materiais utilizados na assistência à saúde ${ }^{(3)}$, somada aos conhecimentos produzidos pelo grupo de pesquisa "Controle de Infecção Relacionada com Procedimentos de Assistência", com cadastro no Conselho Nacional de Desenvolvimento Científico e Tecnológico - CNPq. Os aspectos considerados no desenvolvimento foram baseados na busca integrada do portal BIREME acessando-se as bases de dados LILACS, MEDLINE, Biblioteca Cochrane, SciELO, sem restrição de idiomas e com data de publicação dos estudos até 2009. O estudo foi desenvolvido com a abordagem de cada um dos itens que constituem riscos potenciais associados ao reúso de materiais de uso único.

\section{DESENVOLVIMENTO}

\section{Integridade e funcionalidade}

$\mathrm{Na}$ avaliação quanto à integridade de materiais reusados, estudos que utilizaram como corpos de prova cateteres vasculares evidenciaram danos, desgaste na sua superfície $^{(4,5)}$, aumento da rigidez e quebra ${ }^{(6)}$. As metodologias empregadas por estes trabalhos incluíram microscopia eletrônica ${ }^{(6)}$ e inspeção visual com ampliação de até 30 vezes ${ }^{(4)}$. Devido ao risco de quebra desses dispositivos dentro do corpo humano e suas consequências para o paciente, recomenda-se limitar o número de reúsos aos quais o material será submetido. Um dos parâmetros que devem ser considerados por uma instituição de assistência à saúde para estabelecer o número máximo de reúsos é o custo do material, que levou a desconsiderar a orientação do fabricante para um único uso. Mesmo antes de atingir o número máximo predeterminado de reúsos, a inclusão de uma etapa de avaliação cuidadosa na rotina, com a utilização de recursos intensificadores de imagem, deve fazer parte do protocolo para garantir a integridade física do dispositivo. Além do risco de quebra, o desgaste da estrutura dos materiais decorrente dos procedimentos inerentes à limpeza pode contribuir para a retenção de micro-organismos, além de outros resíduos orgânicos e inorgânicos ${ }^{(5)}$. Ressalta-se que materiais de uso único são fabricados a partir de matérias-primas que não resistem a produtos e artefatos abrasivos. Outras alterações físicas detectadas nos materiais - como mudanças na coloração, rebarbas e trincas devem ser valorizadas como critério para o descarte do material.

$\mathrm{O}$ estudo da funcionalidade dos materiais de uso único reusados é a etapa mais problemática, uma vez que não há como detectar a sua falha, a não ser no momento da sua utilização. Mesmo para os materiais comercializados como de "não uso único", são raros os recursos para testar previamente a sua funcionalidade. Pelo racional teórico, todo material de uso único reusado pode apresentar desempenho prejudicado quando comparado ao de primeiro uso, uma vez que o fabricante se responsabiliza por um único uso. Koh e Kawara $^{(7)}$ atestaram funcionalidade prejudicada em materiais reusados ao avaliar a capacidade dos trocartes em perfurar a pele, assim como a força tênsil e a resistência à pressão da água em clipes endoscópicos. Nenhuma justificativa de ordem financeira sustenta o risco da funcionalidade prejudicada nos materiais de uso único reusados. Deve fazer 
parte do protocolo de validação do reúso dos materiais o monitoramento sistemático e documentado, considerando a avaliação dos usuários dos materiais em questão, preferencialmente de forma cegada, ou seja, a emissão de parecer sem o conhecimento de que o material seja novo ou reusado.

\section{Limpeza}

A garantia de um reprocessamento seguro, sem dúvida, coloca a limpeza como a etapa mais importante desse processo, a qual compreende a remoção de micro-organismos e resíduos orgânicos e inorgânicos ${ }^{(8)}$. Este procedimento deve ser feito após pré-umectação do material sujo, este deve ser deixado imerso em água por alguns minutos. Deve-se utilizar detergente adequado (neutro, enzimático ou alcalino) de acordo com o grau de sujidade e fricção das superfícies externas e internas com escovas de cerdas e dimensões adequadas. Ressalta-se que os materiais de uso único geralmente não são desmontáveis, o que dificulta sobremaneira a limpeza manual e automatizada. Esta última pode ser realizada utilizando-se lavadoras ultrassônicas, que são indicadas para materiais com espaços internos que escovas não conseguem atingir. Por meio da cavitação ou vacuolização, a sujidade aderida na superfície dos materiais é descolada. Para materiais que permitem encaixe, a lavadora ultrassônica com jato pulsátil está indicada como a melhor tecnologia.

A comparação da eficácia da limpeza manual ultrassônica com a da ultrassônica com jato pulsátil em materiais canulados evidenciou que esta última foi significativamente mais eficaz. No que se refere à remoção de hemoglobina, carboidratos, proteínas e endotoxinas, a limpeza ultrassônica com jato pulsátil reduziu em $98 \%$ ou mais a quantidade dessas substâncias e foi capaz de reduzir em $2 \log 10$ a carga microbiana, enquanto a limpeza manual e a ultrassônica sem o recurso do jato pulsátil a reduziram em menos de $1 \log 10^{(8)}$.

O enxágue abundante, com água minimamente filtrada (potável) para a remoção completa dos produtos utilizados na limpeza e desinfecção é fundamental, pois resíduos destes produtos químicos podem provocar reações inflamatórias graves ${ }^{(8)}$.
Há critérios estabelecidos para a avaliação do risco no reprocessamento de materiais de uso único baseados na avaliação do grau de dificuldade de limpeza. São materiais de baixo risco, aqueles desmontáveis ou parcialmente desmontáveis, transparentes para avaliação do resíduo de sujidade, que sejam blindados internamente ou permitam a entrada e a saída de água, conformação que permite o uso de artefatos para a limpeza dos espaços internos e possibilita a limpeza similar à realizada no material equivalente que não seja de uso único ${ }^{(9)}$. $\mathrm{O}$ correto dimensionamento dos riscos realizado por meio desses critérios pode subsidiar os estabelecimentos de saúde na decisão pelo reúso dos materiais de uso único.

\section{Biofilmes}

Os biofilmes são formados espontaneamente na natureza pela adesão irreversível de microorganismos em superfícies inertes, formando microcolônias protegidas por uma matriz polimérica - exopolissacarídeos ${ }^{(10)}$.

Materiais utilizados na assistência à saúde são passíveis à formação de biofilmes, principalmente aqueles com lúmens ou outros espaços internos. Estas formações têm sido associadas a infecções onde há material implantado, como cânulas traqueais, cateteres venosos centrais e vesicais, agravadas pelo aumento da resistência a biocidas ${ }^{(10)}$. Contrariamente, a associação de infecções pósprocedimentos com materiais reusados contendo biofilmes ainda é muito incipiente em nosso meio.

Alguns micro-organismos, como Pseudomonas sp., micobactérias, Escherichia coli e Staphylococcus aureus, apresentam a propriedade de liberar o exopolissacarídeo quando depositados em uma superfície inerte e molhada, formando rapidamente colônias organizadas. Entende-se que a formação de biofilmes é um mecanismo de defesa dos microorganismos para a sua sobrevivência e que esta estrutura começa a se formar nos materiais em curto período de tempo, a partir de uma hora de sua presença no material. Após a formação do biofilme, se os métodos de "quebra" não forem aplicados na superfície do material, agentes desinfetantes e esterilizantes não terão acesso aos micro-organismos da camada de biofilme; 
por isso a qualidade da água utilizada no enxágue dos materiais é de extrema importância na gênese dos biofilmes, justificando-se a utilização de filtros bacterianos ${ }^{(11)}$.

Uma vez formado o biofilme, a remoção mecânica é uma das formas mais eficazes de eliminá-lo, por meio da fricção da superfície dos materiais com o auxílio de escovas. No caso de impossibilidade do uso destas, a lavadora ultrassônica é um recurso indicado. Há pesquisas desenvolvidas por indústrias sinalizando sucesso na remoção dos biofilmes por meio da utilização de detergentes enzimáticos específicos para elementos que constituem exopolissacárides, o que caracteriza um avanço.

Conforme já foi mencionado, os materiais comercializados como de uso único não são desmontáveis, o que dificulta a remoção dos biofilmes. Este fato deve ser considerado no momento da decisão pelo reúso e também no número de reúsos.

\section{Esterilidade}

A maioria dos materiais de uso único são termossensíveis, portanto a esterilização possível é aquela que utiliza baixa temperatura. Sabe-se que a eficácia desses métodos de esterilização está na dependência das propriedades de difusão e contato do agente esterilizante com a superfície do material. Por isso a escolha do agente esterilizante de alta difusibilidade e a garantia da ausência de sujidade residual e de biofilmes são fatores prioritários para a eficácia da esterilização. Ressalta-se que a difusão do agente esterilizante fica prejudicada em material não desmontável, que é o caso dos de uso único.

Silva e Pinto ${ }^{(4)}$ simularam a reutilização de materiais de uso único utilizando, além de outros métodos, contaminação prévia das amostras caracterizando desafio, num tamanho de inóculo na ordem de $10^{7}$ UFC de esporos de Bacillus subtilis var. niger. Apesar das discussões quanto ao uso desse tipo de desafio cuja contraargumentação sustenta que tal inóculo não reflete a realidade, recomenda-se sua inclusão na validação dos protocolos de reúso.

\section{Endotoxinas}

Endotoxinas são definidas como lipopolissacarídeos (LPS) integrantes da membrana de bactérias gram-negativas. Sua liberação ocorre quando há morte (neste caso em grande quantidade), divisão ou crescimento bacteriano $^{(12)}$. As endotoxinas constituem riscos pela sua estabilidade ao calor, pois são inativadas somente a temperaturas acima de $180^{\circ} \mathrm{C}$, e pela capacidade de produzir reações que podem variar de calafrios a choque irreversível e morte ${ }^{(13)}$. Além desses sintomas, as endotoxinas podem causar síndromes tóxicas oculares $^{(14)} \mathrm{e}$ induzir a ocorrência de solturas assépticas em implantes ortopédicos ${ }^{(15)}$.

Em razão dos riscos, há autores que recomendam evitar o contato dos materiais com água de torneira não controlada quanto à contaminação microbiana, pele e instrumentos de limpeza molhados. Além disso, recomendam que os materiais sejam processados, embalados e esterilizados no menor tempo possível, de forma a limitar o tempo para a contaminação e crescimento bacterianos, com consequente redução dos riscos ${ }^{(13,16)}$.

\section{Proteínas e príons}

A ocorrência de "Toxic anterior segment syndrome" (TASS), ou síndrome tóxica do segmento anterior do olho e doenças priônicas, tem chamado a atenção para o impacto de resíduos proteicos nos materiais utilizados na assistência à saúde. TASS é uma complicação rara, relacionada à cirurgia intraocular, geralmente a cirurgia de catarata. Ocorre quando agentes não infecciosos entram em contato com o segmento anterior do olho, produzindo resposta inflamatória local, com resolução espontânea ou complicada, podendo causar danos permanentes, inclusive cegueira ${ }^{(14)}$.

As causas de TASS estão associadas à presença de endotoxinas, resíduos de viscoelástico ou quaisquer outras substâncias exógenas, como talco e resíduos de detergentes, que permanecem no material mesmo após a esterilização ${ }^{(14)}$. Dessa forma, a qualidade da limpeza e do enxágue do instrumental é fundamental na prevenção do TASS, que é prejudicada principalmente em materiais não desmontáveis, como é o caso de materiais de uso único.

As doenças priônicas são causadas por partículas protéicas menores que os vírus e isentos de material genético, sendo a mais relevante a de Creutzfeldt-Jakob, com 
prevalência de $1 / 1.000 .000^{(17)}$. A doença é caracterizada pela ocorrência de encefalopatia espongiforme, com evolução rápida e fatal, e pode ser transmitida por meio de materiais utilizados na assistência à saúde, especialmente nos procedimentos neurocirúrgicos. Esses patógenos não são inativados pelos meios convencionais de esterilização. Teoricamente, como se trata de uma proteína, a atenção deve estar voltada para a remoção das partículas priônicas, e não para sua inativação, o que valoriza a fase da limpeza ${ }^{(17)}$.

$O$ período de incubação das doenças priônicas pode durar anos, o que impossibilita o estabelecimento de diretrizes voltadas para o rastreamento de pacientes e materiais com suspeita ou certeza de contaminação priônica. Por outro lado, por ora, são raras as ocorrências deste tipo de doença no Brasil, o que não justifica, por enquanto, adotar diretrizes diferenciadas para materiais que entram em contato com tecidos com alto risco de contaminação por príons, especialmente o sistema nervoso central.

Para ressaltar, mais uma vez, a característica não desmontável da maioria dos dispositivos de uso único, que não permite acesso a todas as superfícies para limpeza, cumpre referir que sua reutilização é temerária quando se considera a gravidade das doenças priônicas.

\section{Resíduos tóxicos}

Um dos riscos associados ao reúso de materiais de uso único são os resíduos tóxicos dos produtos empregados na limpeza e esterilização. No caso do óxido de etileno (ETO), processo de esterilização comumente utilizado nos materiais termossensíveis, certos materiais podem absorver maiores quantidades do gás ETO e dos seus subprodutos. Em razão da grande variedade de materiais utilizados na assistência à saúde, as cinéticas de adsorção e absorção dos resíduos do ETO e seus subprodutos constituem um desafio para a reutilização dos materiais de uso único ${ }^{(18)}$.

Estes fatos revelam a necessidade de métodos específicos e sensíveis de investigação da toxicidade desses materiais. A norma ISO $10993-5^{(19)}$, que trata da avaliação biológica de materiais utilizados na assistência à saúde, lista diversos métodos para a avaliação in vitro da toxicidade celular desses materiais. De forma geral, esses métodos consistem em colocar as amostras em contato com culturas de células, as quais revelarão a presença ou não da toxicidade do material testado. Destarte, é recomendável que os materiais sejam avaliados quanto à toxicidade, incluindo-se esta atenção na elaboração do protocolo de validação para o reúso de materiais de uso único.

\section{CONSIDERAÇÕES FINAIS}

Este estudo possibilitou uma reflexão avaliativa sobre a complexidade da elaboração de protocolos de reúso ao dimensionar os riscos da reutilização de materiais de uso único.

A legislação vigente sobre reúso está incompleta, pois não contempla todos os riscos inerentes à reutilização destes materiais. Além disso, transfere totalmente a responsabilidade da segurança no reúso às instituições de saúde, sem estabelecer métodos e parâmetros mínimos de segurança que devam ser observados na elaboração, validação e implantação de protocolos de reúso. Com essa deficiência, a legislação não garante proteção total à saúde do usuário com relação aos materiais em questão.

Por outro lado, nem todos os materiais comercializados como de uso único precisam ser descartados após o primeiro uso. Este é o caso, por exemplo, daqueles sem espaços internos e de conformação simples, cuja funcionalidade possa ser garantida. A título de exemplo, cateteres de eletrofisiologia são dispositivos passíveis de validação, assim como alguns materiais não críticos e semicríticos. O descarte desnecessário de materiais utilizados na assistência à saúde é uma questão de sustentabilidade e responsabilidade social, uma vez que o montante de resíduos gerados é significativo.

COMPLEXITY IN THE DEVELOPMENT OF A PROTOCOL FOR THE REUSE OF SINGLE USE DEVICES

\section{ABSTRACT}

In Brazil, the reuse of single use devices is a reality. Specific 2.606/2006 Resolution of the National Sanitary Surveillance Agency, which deals with the guidelines for the development, validation and implementation of 
protocols for the reprocessing of medical products, emphasizes microbiological aspects, recommending the need for detailed description of the stages of cleaning, rinsing, drying, disinfection, packaging, sterilization, labeling and packaging. We understood that to develop a protocol for reprocessing, other safety-related aspects should be included, such as assessing the integrity and functionality of the reused materials, the presence of biofilm, endotoxins, residues of proteins and prion and other toxic waste products used for cleaning and sterilization. Based on these weaknesses in the legislation, this article proposed discussing other risks inherent to the reuse of single use devices besides those directly related to infection.

Key words: Risk management. Safety. Nursing. Sterilization.

\section{COMPLEXIDAD EN LA ELABORACIÓN DE UN PROTOCOLO PARA LA REUTILIZACIÓN DE MATERIALES DE USO ÚNICO}

\section{RESUMEN}

En Brasil, la reutilización de materiales de uso único es una realidad. La Resolución Específica 2.606/2006 de la Agencia Nacional de Vigilancia Sanitaria (ANVISA), que dispone sobre las directrices para la elaboración, validación e implantación de los protocolos de reprocesamiento de productos médicos, enfatiza aspectos microbiológicos y recomienda la descripción detallada de las fases de limpieza, enjuague, secado, desinfección, empaquetado, esterilización, etiquetado y almacenamiento. Se entiende que para elaborar un protocolo de reprocesamiento, otros aspectos relacionados a la seguridad deben de ser incluidos, como la evaluación de la integridad y de la funcionalidad de los materiales reutilizados, de la presencia de biofilms, de endotoxinas, de residuos proteicos, de partículas priónicas y de otros residuos tóxicos de los productos utilizados en la limpieza y esterilización. Frente a estas fragilidades de la legislación, el presente artículo de reflexión propone discurrir sobre los otros riesgos inherentes a la reutilización de materiales de uso único, además de aquéllos relacionados a la infección.

Palabras clave: Control de Riesgo. Seguridad. Enfermería. Esterilización.

\section{REFERÊNCIAS}

1. Araujo MFM, Caetano JA, Damasceno MMC, Gonçaly TC. Reutilização de agulhas e seringas descartáveis por um grupo de diabéticos. Ciênc Cuid Saúde 2009 Jan/Mar; 8(1):93-100.

2. Centro Cochrane do Brasil. Segurança e eficácia dos cateteres de eletrofisiologia. São Paulo, 2005.

3. Brasil. Ministério da Saúde. ANVISA. Resolução Específica 2.606. Dispõe sobre as diretrizes para elaboração, validação e implantação de protocolos de reprocessamento de produtos médicos e dá outras providências. Brasília; 2006.

4. Silva MV, Pinto TJA. Reutilização simulada de produtos medico-hospitalares de uso único, submetidos à esterilização com óxido de etileno. Rev Bras Cienc Farm. 2005; 41(2):181-9.

5. Bathina MN, Mickelsen S, Brooks C, Jaramillo J, Hepton T, Kusumoto FM. Safety and efficacy of hydrogen peroxide plasma sterilization for repeated use of electrophysiology catheters. J Am Coll Cardiol. 1998 Nov;32(5):1384-8.

6. Granados DL, Jiménez A, Cuadrado TR. Assessment of parameters associated to the risk of PVC catheter reuse. J Biomed Mater Res. 2001;58(5):505-10.

7. Koh A, Kawahara K. Current practices and problems in the reuse of single-use devices in japan. J Med Dent Sci. 2005;(52):81-9.

8. Alpha MJ, Nemes R, Olson N, Mulaire A. Manual methods are suboptimal compared with automated methods for cleaning of single-use biopsy fórceps. Infect Control Hosp Epidemiol. 2006;27(8):811-816

9. Graziano KU, Balsamo AC, Lopes CLBC, Zotelli MFM, Couto AT, Paschoal MLH. Critérios para avaliação das dificuldades na limpeza de artigos de uso único. Rev Latinoam Enferm 2006;14(1):70-6

10. Donlan RM. Biofilms: microbial life on surfaces. Emerg Infect Dis. 2002 Sep;8(9):881-90

11. Vickery K, Ngo QD, Zou J, Cossart YE. The effect of multiple cycles of contamination, detergent washing, and disinfection on the development of biofilm in endoscope tubing. Am J Infect Control. 2009;37(6):470-5.

12. Gorbet MB, Sefton MV. Endotoxin: the uninvited guest. Biomaterials. 2005;26(34):6811-7.

13. Kundsin RB, Walter CW. Detection of endotoxin on sterile catheters used for cardiac catheterization. J Clin Microbiol. 1980;11(3): 209-12.

14. Mathys KC, Cohen KL, Bagnell CR. Identification of unknown intraocular material after cataract surgery: Evaluation of a potential cause of toxic anterior segment syndrome. J Cataract Refract Surg 2008;34(3):465-9.

15. Greenfield EM, Bi Y, Ragab AA, Goldberg VM, Nalepka JL, Seabold JM. Does endotoxin contribute to aseptic loosening of orthopedic implants? J Biomed Mater Res B Appl Biomater. 2005 Jan 15;72(1):179-85.

16. Tessarolo F, Caola I, Nollo G, Antolini R, Guarrera GM, Caciagli P. Efficiency in endotoxin removal by a reprocessing protocol for electrophysiology catheters based on hydrogen peroxide plasma sterilization. Int J Hyg Environ Health. 2006;209(6):557-65.

17. Goveia VR, Moriya GAA, Neto SB, Lacerda RA, Graziano KU. Recomendações para prevenção e controle da disseminação intra-hospitalar de prions: uma revisão bibliográfica. Rev. SOBECC. 2006;11(1): 28-34.

18. Pinto TJA, Graziano KU. Reprocessamento de artigos médicos-hospitalares de uso único. In: Fernandes AT, Fernandes MOV, Ribeiro N Filho. Infecção hospitalar e suas interfaces na área de saúde. São Paulo: Atheneu; 2002. 
p. $1070-8$.

19. International Standard Organization. ISO 10993-5.
2009. Biological evaluation of medical devices Part 5: Tests for cytotoxicity: in vitro methods.

Endereço para correspondência: Kazuko Uchikawa Graziano. Avenida Dr Enéas de Carvalho Aguiar, 419, Cerqueira César, CEP: 05403-000, São Paulo, São Paulo.

Data de recebimento: $11 / 06 / 2010$

Data de aprovação: 25/11/2010 